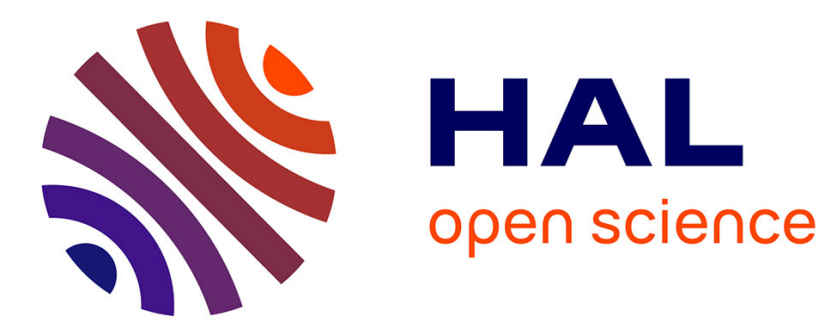

\title{
Further insight into the microstructure of compacted bentonite-sand mixture
}

S. Saba, Pierre Delage, N. Lenoir, Yu-Jun Cui, Anh Minh A.M. Tang, J.D. Barnichon

\section{- To cite this version:}

S. Saba, Pierre Delage, N. Lenoir, Yu-Jun Cui, Anh Minh A.M. Tang, et al.. Further insight into the microstructure of compacted bentonite-sand mixture. Engineering Geology, 2014, 168 (168), pp.141148. 10.1016/j.enggeo.2013.11.007 . hal-01084170

\section{HAL Id: hal-01084170 https://hal.science/hal-01084170}

Submitted on 26 Apr 2018

HAL is a multi-disciplinary open access archive for the deposit and dissemination of scientific research documents, whether they are published or not. The documents may come from teaching and research institutions in France or abroad, or from public or private research centers.
L'archive ouverte pluridisciplinaire HAL, est destinée au dépôt et à la diffusion de documents scientifiques de niveau recherche, publiés ou non, émanant des établissements d'enseignement et de recherche français ou étrangers, des laboratoires publics ou privés. 


\section{Further insight into the microstructure of compacted} bentonite-sand mixture

4

5

Simona Saba ${ }^{1,2}$, Pierre Delage ${ }^{1}$, Nicolas Lenoir ${ }^{1}$, Yu Jun Cui ${ }^{1}$, Anh Minh Tang ${ }^{1}$, JeanDominique Barnichon ${ }^{2}$

7

${ }^{1}$ Ecole des ponts ParisTech, Navier/CERMES, Université Paris-Est

${ }^{2}$ Institut de Radioprotection et Sûreté Nucléaire - IRSN

10

11

12

13

Corresponding author:

18 Ecole des Ponts ParisTech

19 6-8 avenue Blaise Pascal

20 F 77455 MARNE-LA-VALLEE cdx 2

21 France

23 Email : delage@,cermes.enpc.fr

$24 \quad 33164153542$ 


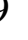

\section{Abstract}

Compacted bricks of bentonite/sand mixture are planned to be used as sealing plugs in deep radioactive waste disposal repositories because of their low permeability, high swelling capacity and favourable properties with respect to radionuclide retention. The isolating capacity of compacted bentonite/sand mixture is closely related to microstructure features that have been often investigated, in particular by using scanning electron microscope (SEM or ESEM) and mercury intrusion porosimetry (MIP).

In this work, microfocus X-ray computed tomography $(\mu \mathrm{CT})$ observations were used in parallel with MIP measurements to further investigate at larger scale the microstructure of a laboratory compacted bentonite/sand disk (65/35\% in mass). Qualitative observation of $\mu \mathrm{CT}$ images showed that sand grains were inter-connected with some large pores between them that were clearly identified in the bimodal pore distribution obtained from MIP measurements. Due to gravitational and to frictional effects along the specimen periphery, a higher density was observed in the centre of the specimen with bentonite grains more closely compacted together. This porosity heterogeneity was qualitatively estimated by means of image analysis that also allowed the definition of the representative elementary volume. Image analysis also provided an estimation of the large porosity in good agreement with MIP measurements.

Keywords: compacted sand-bentonite mixture, sealing plug, radioactive waste disposal, microstructure, mercury intrusion porosimetry, $\mathrm{X}$ ray micro tomography

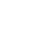




\section{Introduction}

56 In deep radioactive waste disposal concepts, sealing plugs made of compacted

57 bentonite/sand blocks are planned to be used to close the galleries and to limit water 58 transfers. Compacted bentonite/sand plugs are used for their low permeability, high

59 radionuclides retention capability and sealing/swelling abilities when infiltrated by

60 water (e.g. Pusch, 1979; Yong et al., 1986). Once the disposal galleries are closed, plugs

61 will be progressively infiltrated by the pore water of the host rock. They will swell and

62 seal the so-called technical voids of the system, i.e. the voids remaining between blocks

63 and at the interfaces with the rock. These technical voids are estimated at $14 \%$ of the

64 total volume of the plugs by IRSN (Institut de Radioprotection et de Sûreté Nucléaire,

65 the French expert Institution in the field of nuclear safety) in the in-situ SEALEX

66 experiment that they carry out in their Tournemire Underground Research Laboratory.

67

68 Various investigations of the microstructure of compacted bentonites and sand bentonite

69 mixture have been carried out by using mercury intrusion porosimetry (MIP) and

70 scanning electron microscopy (SEM, ESEM, Komine and Ogata, 1999; Villar and

71 Lloret, 2001; Montes-H, 2002; Cui et al., 2002; Lloret et al., 2003; Agus and Schanz,

72 2005; Delage et al., 2006). These techniques require a cautious preliminary dehydration

73 of the samples, most often by freeze-drying. They provide local observations on a small

74 part of millimetric samples. These localized analytical techniques can be fruitfully

75 complemented by use of by microfocus X-ray computed tomography $(\mu \mathrm{CT})$, a high-

76 resolution non destructive $3 \mathrm{D}$ observation technique. The $\mu \mathrm{CT}$ does not need any 
sample pre-treatment and gives further 3D information on the whole sample (including grain size distribution as well as pore size distribution and pore inter-connectivity). Previous applications of $\mu \mathrm{CT}$ have been devoted to the monitoring of hydro-chemomechanical processes (Comina et al., 2008), to the detection of dessication cracks

81 (Gerbrenegus et al., 2006; Mukunoki et al., 2006), to the visualisation of 82 diffusion/hydration phenomena, to the study of fluid movements (Rolland et al., 2003; Rolland et al., 2005; Carminati et al., 2006; Koliji et al., 2006) and to the investigation of the microstructure of compacted bentonite based materials (Kozaki et al., 2001, Van Geet et al., 2005 and Kawaragi et al., 2009). In this work, $\mu \mathrm{CT}$ was coupled to MIP for further microscopic investigation of a compacted bentonite/sand sample.

\section{Material and methods}

88

\section{Material}

The studied material is a compacted mixture of Wyoming MX-80 bentonite ( $65 \%$ in dry mass, commercial name Gelclay WH2) and sand (35\%). The MX80 bentonite contains $92 \%$ of montmorillonite with several other minerals including quartz, alumina, and hematite (Tang et al., 2008). The sand is quartz sand (commercial name TH1000).

The sand-bentonite mixture was provided in boxes containing a powder with an initial water content of $10.2 \%$ and a suction of $73.3 \mathrm{MPa}$ measured with a chilled mirror dew point tensiometer (Decagon WP4). Samples of sand and bentonite were also provided separately. The grain size distribution of the bentonite powder obtained by dry sieving is presented in Figure 1 together with that of the deflocculated bentonite obtained by sedimentation. The grain size distribution of the sand is also plotted in Figure 1. 
101 The grain size distribution curves show that the bentonite powder grains are larger than

102 the sand grains with $D_{50}$ values of 1.2 and $0.6 \mathrm{~mm}$ respectively. Both curves are

103 representative of well sorted materials. The unit mass of the bentonite particles that

104 constitute the bentonite grains was measured by using a pycnometer with water and was

105 found equal to $2.77 \mathrm{Mg} / \mathrm{m}^{3}$ in agreement with published data (Madsen, 1998; Karnland

106 et al., 2006). The unit mass of the bentonite powder was determined by using a

107 pycnometer with a non aromatic hydrocarbon fluid (commercial name Kerdane). The

108 bentonite grains appeared to be stable once immersed in Kerdane and a value of

$1092 \mathrm{Mg} / \mathrm{m}^{3}$ was obtained. This value could suffer from some uncertainty due to possible

110 Kerdane infiltration into the grains. A comparable unit mass value was however

111 obtained from the cumulative pore size distribution curve presented later in Figure 2

112 that allows determining the unit mass of the bentonite grains from the value of inter-

113 grains porosity. The unit mass of the sand grains was found equal to $2.65 \mathrm{Mg} / \mathrm{m}^{3}$.

115 Compacted samples were prepared by uniaxial static compaction (strain rate of 0.1

$116 \mathrm{~mm} / \mathrm{min}$ ) in a cylindrical mould in order to obtain a disk (diameter $50 \mathrm{~mm}$, height 10

$117 \mathrm{~mm})$ at the targeted dry density $\left(1.8 \mathrm{Mg} / \mathrm{m}^{3}\right.$ obtained at a maximum compaction stress

118 of $25.5 \mathrm{MPa}$ ). The sample water content was $10 \%$, resulting in a degree of saturation of

$11955 \%$ and a suction of $76.3 \mathrm{MPa}$. Note that this value is close to that of the powder prior

120 to compaction $(73.3 \mathrm{MPa})$. The slightly higher value could be due to some effects of

121 evaporation during the process of compaction. In any case, these small changes in

122 suction after compaction are consistent with the observations of Li (1995), Gens et al.

123 (1995) and Tarantino and De Col (2008) on soils compacted on the dry side of Proctor 
124 optimum. It confirms that suction is governed by aggregates that are not much affected

125 by the compaction. As a consequence, there is little dependency of the water retention

126 properties on the sample density in compacted bentonite based materials.

\section{Mercury intrusion porosimetry}

128 The pore size distribution of the compacted samples was measured on freeze dried

129 samples by using an Autopore IV 9500 mercury intrusion porosimeter (Micromeritics)

130 working to a maximum pressure of $230 \mathrm{MPa}$. Instantaneous freezing was carried out by

131 plunging small samples (volume $0.40 \mathrm{~cm}^{3}$ ) into slush nitrogen (liquid nitrogen at cooled

132 down from $-195^{\circ} \mathrm{C}$ to $-210^{\circ} \mathrm{C}$ by vacuum application, Delage et al., 2006). In such

133 conditions, there is no nitrogen boiling around the samples when plunging them into

134 nitrogen, resulting in an optimized quick freezing and good microstructure preservation.

135 The intruded porosity was determined from the total volume of mercury intruded into

136 the sample and the pore size distribution was obtained, in a standard fashion, assuming

137 parallel, cylindrical nonintersecting pores of different radii, using the Autopore IV 9500

138 V1.09 standard software package. The intruded porosity was systematically compared

139 to the total porosity obtained by standard methods so as to detect the smaller porosity

140 (entrance equivalent diameter smaller than $5.5 \mathrm{~nm}$ ) not intruded by mercury at the

141 highest applied pressure (200 MPa).

\section{Microfocus X-ray tomography and image analysis}

143 Microfocus $\mathrm{x}$-ray computed tomography $(\mu \mathrm{CT})$ was used to examine in three

144 dimensions the internal microstructure of the compacted bentonite/sand mixtures. $\mu \mathrm{CT}$

145 is a non-destructive observation technique that has proven to be useful in the

146 investigation of various geological porous media including compacted bentonite 
147 (Kozaki et al., 2001), bentonite pellet/powder mixture (Van Geet et al., 2005) and 148 compacted bentonite/quartz mixture (Kawaragi et al., 2009). $\mu \mathrm{CT}$ consists firstly of

149 recording a set of two-dimensional X-ray radiographs of an object at several angles

150 (typically at $180^{\circ}$ or $360^{\circ}$ ) and secondly in reconstructing the $3 \mathrm{D}$ slices from the 151 radiographs using a mathematical algorithm. The final $3 \mathrm{D}$ image of the internal 152 structure is obtained by stacking the slices. The final measurement is the attenuation 153 coefficient to x-ray which depends on the mass density and the atomic number of the 154 object (Ketcham and Carlson, 2001; Van Geet et al., 2005).

156 The $\mu \mathrm{CT}$ scans presented here were carried out with the device of the Navier laboratory

157 (Ecole des Ponts ParisTech), an "Ultratom" device specifically designed and 158 manufactured by RXsolutions (France). Images were reconstructed using the software 159 Xact-reconstruction developed by RXsolutions. The system is a dual-head and dual160 imager scanner; two sources [a nano-focus xs-160hpnf/GE-Phoenix $(160 \mathrm{kV}, 15 \mathrm{~W}, 0.9$ $161 \mu \mathrm{m}$ min spot size $)$ and a micro-focus xs-225d/GE-Phoenix $(225 \mathrm{kV}, 320 \mathrm{~W}, 5 \mu \mathrm{m}$ min 162 spot size)], two interchangeable imagers: [HD camera PhotonicScience VHR $163(4008 \times 2672$ pixels, $9 \mu \mathrm{m}$ pixel size $)$ and a flat-panel-CsI scintillator-Varian

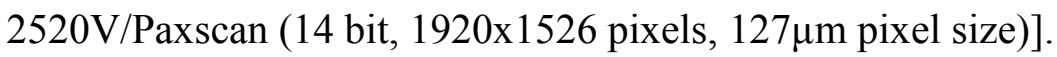

166 A micro-focus source was used together with a flat panel. The X-ray source parameters 167 were a voltage of $140 \mathrm{kV}$ with an intensity of $210 \mu \mathrm{A}$, a source power resulting in a spot 168 size below or equal to the spatial resolution, here a voxel size of $30 \mu \mathrm{m}$ (a voxel 169 describes a Volume Pixel which is the smallest distinguishable box-shaped portion of a 170 three-dimensional image). The sample was scanned using 1440 projections on $360^{\circ}$ 
171 with an exposure time of $0.2 \mathrm{~s}$. Each projection was integrated on $4 \mathrm{~s}$ (average of 20

172 frames) in order to obtain a good signal-to-noise ratio. The total scanning time was

173 about an hour and a half. The final 3D image is a 16 bit type with a size of

$1741840 \times 1840 \times 386$ voxels. The image analysis and treatment was then carried out by using

175 ImageJ, a public domain Java image processing program (Rasband, 1997-2012). Note

176 that the image was first converted to 8 bit for size reasons.

\section{Results}

\section{Pore size distribution}

179 The pore size distribution determined at a dry density of $1.8 \mathrm{Mg} / \mathrm{m}^{3}$, a water content of

$18010 \%$ and a suction of $76.6 \mathrm{MPa}$ is presented in terms of cumulative and density

181 functions curves in Figure 2. The bimodal curve obtained is comparable to that of 182 samples compacted dry of optimum (Ahmed et al., 1974; Delage et al., 1996; Romero et 183 al., 1999 among others) and also with the results of Cui et al. (2002), Lloret et al. 184 (2003), Agus and Schanz, (2005) on compacted bentonite materials. The PSD curve

185 indicates that the smaller pores population (micropores) has a mean entrance diameter 186 of $0.19 \mu \mathrm{m}$ and the larger pore population (macro-pores) has a mean entrance diameter 187 of $22 \mu \mathrm{m}$. Note that the intrusion of mercury into the specimen starts at quite a low 188 pressure, evidencing a largest diameter of $360 \mu \mathrm{m}$, the upper limit of the method. The 189 total porosity (0.337) calculated in a standard fashion by macroscopic volume

190 measurements is also plotted in Figure 2. The smaller value of the porosity intruded by 191 mercury (0.273) confirms that pores with an entrance diameter smaller than $5.5 \mathrm{~nm}$ (the 192 lower limit of MIP) could not be intruded by mercury. This feature is typical of 
193 compacted bentonites and strongly depends on the water content (the higher the water

194 content, the higher the smallest porosity, see Delage et al., 2006).

\section{Microfocus X-ray computed tomography ( $\mu$ CT)}

\section{Image Observation}

198 The reconstructed 3D volume of a compacted sample of bentonite/sand mixture at a dry

199 density of $1.8 \mathrm{Mg} / \mathrm{m}^{3}$ and a water content of $10 \%$ is presented in Figure 3 . The position

200 of the plane where the cross section has been done is indicated. The horizontal cross

201 section at $4 \mathrm{~mm}$ from the top of the sample is provided in Figure 4.

202

203 The $\mu \mathrm{CT}$ technique is able to distinguish the various components according to their

204 density and atomic composition (the grey level range goes from white representing high

205 attenuating material to black representing void). A clear distinction can be made

206 between the clearer sand grains and the less clear larger bentonite powder grains

207 (hydrated at a gravimetric water content of 10.6\%), even though their respective

208 densities are not so different (around $2 \mathrm{Mg} / \mathrm{m}^{3}$ for the bentonite grains and $2.65 \mathrm{Mg} / \mathrm{m}^{3}$

209 for sand grains). This is due to the atomic composition difference. One can also observe

210 in Figure 4 that the sample density is not strictly homogeneous with more voids

211 observed around the sample and a larger density with less voids in the centre. This

212 shows that, unsurprisingly, compaction was less effective around the sample along the

213 ring against which friction effects resulted in looser compaction. Detailed observation

214 made on a zoom taken close to the sample perimeter also shows that the bentonite

215 powder grains remain clearly apparent around the sample and that they are apparently 
216 more frequent than in the centre. In the centre, powder grains appear to be more

217 compacted one against another, resulting in a denser structure.

218

219 Inspection of Figure 4 also shows that the bentonite/sand mixture is not really 220 homogeneous and that sand grains and powder grains appear to be somewhat 221 segregated. As indicated in the Figure, aggregations of powder grains are observed in some locations and sand grain packings with inter-grains pores in other locations. This segregation, probably resulting from the difference in density between the bentonite

224 powder and the sand grains, is not compatible with the common statement that, in a 35-

$22565 \%$ sand/bentonite mixture, sand grains should be homogeneously scattered among a

226 (supposedly finer) clay matrix. Conversely, it seems that, due to segregation, some continuity between the sand grains is observed. As a consequence, there could be some continuity and interconnection of the pores located between sand grains.

230 Note that this segregation is probably depending on the process adopted here of pouring 231 the dry mixture into the ring. It would hence be interesting to investigate the effects of 232 two possible options for preparing more homogeneous sand-bentonite mixture: i) by 233 previously moisturizing the mixture so as to make the clay grains stick to sand particles,

234 resulting in less segregation than in the dry mixture, provided the wet mixture is 235 thoroughly mixed prior to being poured into the ring and ii) by grinding bentonite grains 236 to smaller sizes. Obviously, the heterogeneity observed here is typical of the preparation 237 procedure of pouring a dry mixture into the compaction ring. 
239 A more detailed examination of the voids configuration shows that many voids are

240 located between sand grains. Around the sample, some voids are also located between

241 powder grains but this is less true in the denser centre in which bentonite grains appear

242 to be aggregated together. This means that the maximum compression stress, in spite of

243 being as high as $25.5 \mathrm{MPa}$, is not high enough to allow the intrusion of clay particles

244 (hydrated at a water content of $14.5 \%$ with a $76.6 \mathrm{MPa}$ suction) into the pores located

245 between the sand grains. This high compression stress only allows some aggregation of

246 bentonite grains as observed in the centre (around 8 grains of various diameters are

247 aggregated in the circle indicated). This slight deformability of dry grains under high

248 stresses is compatible with the observation made above about the small suction

249 variations observed when compacting samples in dry conditions: compaction affects the

250 assembly of bentonite grains but not significantly the bentonite grains themselves, the

251 microstructure of which is governing suction.

252

253 Visual observation of two cross sections close to the bottom and to the top of the sample

254 also showed that the pore distribution was not homogeneous along the axial direction,

255 with more large pores and large particles observed in the bottom of the sample. This is

256 related to segregation effects during sample preparation. When pouring the powder into

257 the compaction mould, the largest grains first tumble resulting in more macropores at

258 the bottom. Indeed, this problem could be solved by using wet mixture with bentonite

259 grains sticking along sand grains and then reducing segregation.

261 Figure 4 provides further information about the interpretation of the PSD curves

262 provided in Figure 2, in which one observes that mercury intrusion started in 
macropores with an entrance diameteras large as $330 \mu \mathrm{m}$ and an average diameter of the corresponding pore population equal to $22 \mu \mathrm{m}$. This size is compatible with the intergrain pores observed in $\mu \mathrm{CT}$ in Figure 3. Given that the sample tested by MIP was extracted from the specimen centre where bentonite grains are more closely compacted

267 together, this pore population is mainly related to the pores located between the sand 268 grains. The clear presence of the pore inter-grains population in the PSD curve confirms 269 the interconnection of inter-grains pores along the grain skeleton that was suspected 270 from the $\mu \mathrm{CT}$ image and commented above. Hence, the bimodal porosity that is 271 generally related to inter-aggregate and intra-aggregate pores in soils compacted dry of 272 optimum (Ahmed et al 1974, Delage et al. 1996, Romero et al. 1999) is due here to the 273 nature of the mutual arrangement of sand and bentonite powder grains. Indeed, the 274 inter-aggregate average entrance pore diameter observed by Delage et al. (1996) in a compacted low plasticity Jossigny silt is $8 \mu \mathrm{m}$ whereas Romero et al. (1999) detected

276 inter-aggregates pores close to $2 \mu \mathrm{m}$ in compacted Boom clay. The significantly larger 277 average entrance pore diameter detected here is too large to be representative of inter278 aggregate pores as in the case of standard compacted soils. It is linked to the connected inter-grains pores observed along the sand skeleton in $\mu \mathrm{CT}$.

Image analysis

281 Further investigation of the microstructure was carried out by using the ImageJ image 282 analysis software. The first step was to reduce noise by applying a 3D median filter with 283 a 1 pixel radius. Then, a segmentation of the image is needed in order to isolate pores 284 from the other existing phases. The choice of the threshold value is made by using the 285 "mixture modelling" plug in. The mixture modelling technique is a histogram based 286 technique that assumes that the histogram distribution is represented by two Gaussian 
curves. The histogram is then separated in two classes using a Gaussian model and a threshold value of 73 is then calculated as the intersection of the two Gaussians. Figure 5 shows the histogram of the image on a linear (black) and logarithmic (grey) scale. The

290 linear graph doesn't exhibit two clearly distinct peaks because the number of pore's 291 voxels is too small compared to that of the grains. However the logarithmic graph

292 evidences a non-symmetrical shape that indicates the presence of the smaller pore population. The two Gaussians are then fitted using the "mixture modelling" plug in as seen in the Figure 5 represented by the white (continuous and dashed) curves.

Figure 6 shows an image at different stages before segmentation: a) initial state; b) after applying a 3D median filter; c) after applying a 73 threshold value (Figure 5) and d) the segmented image. An investigation on the effect of the size of the studied volume on the calculated porosity was done. To do so, the porosity was calculated by using the histogram of the segmented image and by dividing the number of black voxels by the total number of voxels. Starting from the middle horizontal cross section of the sample at different positions (see Figure 7a), cubic volumes were selected with sides starting

303 from 21 to 271 pixels. The side on the $z$ direction is limited by the height of the sample

$304(10 \mathrm{~mm})$ that corresponds to a maximum thickness of 271 pixels. $x$ and $y$ were 305 afterwards increased until 700 resulting in a parallelepiped volume. The porosity values 306 calculated with respect to the considered volumes are plotted in Figure 7. The curves 307 start with some irregularities and then stabilise. Some curves continuously and slowly 308 increase (bottom and right in Figure 7a). These increases suggest a spatial heterogeneity 309 of the porosity. Indeed, when the studied volume increases, porosity increases because 310 some zones located on the side of the specimen with higher porosity are more and more 
311 included into the volume. Stabilization is observed for volumes greater than $20 \times 10^{6}$

312 voxels. This volume corresponds to a cube with a side approximately equal to the height

313 specimen i.e. 271 pixels. It can hence be considered as a Representative Elementary

314 Volume (REV). This side size corresponds to 9 adjacent grains $\left(D_{50}\right.$ mixture $=0.9 \mathrm{~mm}$

$315=30$ voxels) in accordance with previous studies (e.g. Razavi et al., 2007).

316

317 The spatial distribution of the porosity is now investigated at different locations along

318 the $x$ and $y$ directions by using volumes with heights equal to 271 pixels. The locations

319 of the volumes sections investigated are presented in Figure 8. Figure 9 shows the

320 variation of porosity with respect to $x$ and $y$ (volumes 1 to 12 in Figure 8). A clear

321 difference is observed in the porosity values between the border ( $x, y=160$ and 1515)

322 and the centre. A significant difference in porosities is also noticed for $x$ (or $y$ ) varying

323 between 1244 and 1515 while $y$ (or $x$ ) equals 925 . It corresponds to cubes 5 and 6,11

324 and 12 in Figure 8. The porosity variation at these points is not smooth like in the others

325 but the slope is steep showing a sudden change in porosity. It confirms the slow

326 increase observed in the REV study (Figure $7 \mathrm{~b}$ ), since it corresponds to the same

327 positions (right for cubes 5 and 6 and bottom for cubes 11 and 12).

328

329 The same study is now made on concentric rings having a height of 271 pixels and a

330 width of 167 pixels starting from the centre (radius from 0 to 167) to the contour (radius

331 from 501 to 835 , see Figure 10).

332

333 The porosities obtained with respect to the radius are presented in Figure 11. The 334 smallest detail that can be identified in the $\mu \mathrm{CT}$ images is defined by the size of the 
335 voxel $(30 \mu \mathrm{m})$. The porosity estimated by image analysis only concerns pores with a 336 diameter larger than 3 voxels (partial volume effect). The value of the cumulated

337 porosity of pores larger than $90 \mu \mathrm{m}$ from the PSD curves (Figure 2 ) is 0.0108 . This

338 value is in the same range as that obtained by image analysis in the central part of the 339 sample where MIP was performed (0.0135 porosity for radius smaller or equal to 334

340 voxels). This confirms that, in spite of some limitation related to the voxel size, $\mu \mathrm{CT}$ is 341 an interesting complementary method to MIP for estimating the macropores and giving 342 additional information on the spatial distribution of the porosity.

\section{Discussion}

344 Most of the investigations carried out up to now on compacted soils in laboratory have 345 been obtained from the combined use of MIP and SEM on freeze dried samples. It is 346 commonly accepted that the bimodal pore distribution observed in fine-grained soils 347 compacted dry of optimum is due to the aggregate microstructure of compacted soils, 348 with macro-pores being inter-aggregate pores and micropores being intra-aggregate 349 pores (Ahmed et al. 1974, Delage et al. 1996). In such soils, it has also been 350 demonstrated that compaction has little effect on the sample's suction (Li et al., 1995, 351 Gens et al., 1995, Tarantino and De Col, 2009), given that suction is governed by intraaggregate phenomena (mainly the adsorption of water in the clay fraction, Romero et al., 1999) whereas the change in density are due to the compression of larger interaggregate pores with little effect on the aggregates (Delage, 2009).

356 Compacted bentonites and sand-bentonite mixtures are a special case of compacted

357 soils. They are obtained by compacting powder grains that may have, as observed here, 
358 a size significantly larger than the aggregates in laboratory compacted soils. Compacted 359 bentonites and sand-bentonite mixtures also have quite large values of suction

360 (76.6 MPa here). In the mixture studied here, the powder grains of bentonite $(1.2 \mathrm{~mm}$

361 average diameter) are larger than the sand grains (0.6 $\mathrm{mm}$ average diameter). As in

362 standard compacted soils, suction appeared here not to change significantly before and

363 after compaction (73.3 $\mathrm{MPa}$ in the powder before and $76.6 \mathrm{MPa}$ after compaction),

364 confirming a well known trend in compacted soils.

365

366 Compared to MIP and SEM, $\mu \mathrm{CT}$ provided more information on the larger scale

367 structure, going from the size of the grains (sand and bentonite, $1 \mathrm{~mm}$ order of 368 magnitude) to the size of the specimen $(50 \mathrm{~mm})$, i.e. on a scale much larger and more 369 representative than both MIP and SEM. Interestingly, $\mu \mathrm{CT}$ has been able to distinguish 370 clearly enough the bentonite from the sand grains within the compacted mixture, in 371 spite of small difference in density. Thus, $\mu \mathrm{CT}$ provided interesting complements to 372 MIP and SEM observations, including granules connectivity and distribution through 373 the sample.

374

375 An important point is that $\mu \mathrm{CT}$ observation confirmed that the bentonite grains seem to 376 have not been crushed during compression. They still have an average size compatible 377 with macroscopic grain size measurements and an angular shape with no clear 378 appearance of local grain breakage. This finding is in agreement with the small variation 379 of suction before and after compaction, as suspected from studies in laboratory 380 compacted soils. Suction didn't change because the grains have not been significantly 381 affected by compression, even under $25.5 \mathrm{MPa}$. $\mathrm{CT}$ also provides clear information 
382 about the mutual arrangement of sand and bentonite grains within the mixture, showing 383 that it is not really homogeneous with some continuity observed between sand grains

384 with the bentonite grains (65\% in mass) located within the sand grains assembly ( $35 \%$ 385 in mass). The common hypothesis of having sand grains isolated within a clay matrix is 386 not confirmed and some continuity of the inter-grains porosity is suspected. In the

387 looser zone around the sample, some large pores with a size comparable to that of the 388 inter-grains pores have also been observed between the bentonite grains. These pores, 389 that are likely to exist in less densely compacted sand-bentonite samples, are no longer 390 observed in the denser central zone in which the compaction stress appears to be high 391 enough to aggregate the bentonite grains together.

392

393 In spite of the precautions taken during sample preparation, $\mu \mathrm{CT}$ clearly evidenced that

394 the compacted sand-bentonite mixture was heterogeneous with looser zones all around 395 the sample close to the ring in which compaction was made. This difference could have 396 been better estimated by running MIP tests at different distances from the centre to 397 compare them with the data of Figure 2 obtained in the denser central area. Some 398 segregation probably resulting from the difference in density between the bentonite and 399 the sand grains was also detected by $\mu \mathrm{CT}$. Again, the use of a wetter mixture as 400 commented above could have helped achieving better heterogeneity with a mixture less 401 sensitive to gravity segregation effects during pouring. The heterogeneity observed is 402 certainly linked to the dry mixing preparation procedure used here and this conclusion 403 should not apply to wetter mixture. Note however that bentonite grains were at 404 equilibrium with ambient atmosphere and that this simple condition is likely to be 405 prevailing when preparing mixtures in real disposal system. Indeed, the process of 
406 mixing a wetter bentonite mixture could add some complexity to the process of 407 preparing compacted mixtures.

408 The hydro-mechanical response of the sample should be somewhat influenced by this 409 heterogeneity, with mechanical parameters affected by the stronger central area and the 410 hydraulic conductivity affected by the smaller permeability around the sample.

\section{Conclusion}

413 The $\mu \mathrm{CT}$ investigation of the microstructure of compacted bentonite/sand mixture 414 samples (65/35\% respectively) provided interesting complementary features at larger

415 scale that could not have been identified by using MIP. $\mu$ CT allowed further 416 observation of the mutual arrangement of bentonite and sand grains. The commonly

417 reported assumption that sand grains are present as isolated particles regularly scattered 418 within a clay matrix has not been observed. The results of this study showed that some 419 continuity could be observed between the sand grains with interconnected inter-grains 420 large pores that were also detected by MIP. Note that the large pore population 421 evidenced by MIP comprises pores located between sand grains and also between 422 bentonite grains as well, indicating some connectivity in this pore population.

423

424 A study on the effect of the size of the REV demonstrated that it was necessary to 425 consider a cubic volume with a size of 271 voxels (around 9 grains). The sample 426 heterogeneity due to compaction with a larger porosity around the sample was 427 quantified by carrying a 3D estimation of porosity by using image analysis. 
429 The interconnection of inter-grains pores evidenced here could have some effects during 430 the hydration of the bentonite/sand mixture, at least in the vapour phase, since it could 431 facilitate the propagation of vapour within the mixture through connected inter-grains 432 pores. The question as to whether this porosity remains interconnected and not clogged 433 when bentonite grains start being hydrated remains. It could be examined by conducting 434 a similar investigation at various degrees of hydration. This complementary study could 435 also allow further understanding about achieving better heterogeneity by using wetter 436 sand bentonite mixture less prone to gravity segregation thanks to some possible 437 sticking of bentonite grains to the sand grains. 
Agus S.S. and Schanz T. (2005). Effect of shrinking and swelling on microstructures and fabric of a compacted bentonite-sand mixture. Proceedings of the International Conference on Problematic Soils, Cyprus, 32, 543 - 550.

Ahmed S., Lovell C. W. and Diamond S. (1974). Pore sizes and strength of compacted clay. J. Geotech. Eng. Div. Am. Soc. Civ. Eng., GT4, 407- 425.

Carminati A., Kaestner A., Hassanein R. and Koliji A. (2006). Hydraulic properties of aggregate-aggregate contacts. In: Desrues J, Viggiani G, Bésuelle P (eds.) Advances in $X$ ray tomography for geomaterials. ISTE Ltd, London, UK, 325-331

Comina C., Foti S., Musso G. and Romero E. (2008). EIT oedometer: an advanced cell to monitor spatial and time variability in soil. ASTM Geotechnical Testing Journal 31 (5), 404-412.

Cui Y.J., Loiseau C. and Delage P. (2002). Microstructure changes of a confined swelling soil due to suction controlled hydration. In Unsaturated soils: proceedings of the Third International Conference on Unsaturated Soils, UNSAT 2002, 10-13 March 2002, Recife, Brazil, volume 2, 593-598.

Delage P. (2009). Compaction behaviour of clay: discussion. Géotechnique 59 (1), 75 76.

Delage P., Marcial D., Cui Y.J. and Ruiz X. (2006). Ageing effects in a compacted bentonite: a microstructure approach, Géotechnique 56(5):291-304.

Delage P., Audiguier M., Cui Y.J., and Howat M. (1996). The microstructure of a compacted silt. Canadian Geotechnical Journal, 33 (1): 150-158.

Gebrenegus T., Tuller M. and Muhuthan B. (2006). The application of X-ray computed tomography for characterisation of surface crack networks in bentonite-sand mixtures. In: Desrues J, Viggiani G, Bésuelle P (eds) Advances in X-ray tomography for geomaterials. ISTE Ltd, London, UK: 207-212

Gens A., Alonso E.E., Suriol J. and Lloret A. (1995). Effect of structure on the volumetric behaviour of a compacted soil. Proc. 1st Int. Conf on Unsaturated Soils UNSAT' 95 1, 83-88.

Karnland O., Olsson S. and Nilsson U. (2006). Mineralogy and sealing properties of various bentonites and smectite-rich clay material. SKB report.

Kawaragi C., Yoneda T., Sato T. and Kaneko K. (2009). Microstructure of saturated bentonites characterized by X-ray CT observations. Engineering Geology 106, 51-57

Ketcham R. A. and Carlson W. D. (2001). Acquisition, optimization and interpretation of X-ray computed tomographic imagery : applications to the geosciences. Computers \& Geosciences Vol. 27, 381-400.

Koliji A., Carminati A., Kaestner A., Vulliet L., Laloui L., Fluehler H., Vontobel P. and Hassanein R. (2006). Experimental study of flow and deformation in aggregated soils using neutron tomography. In: Desrues J, Viggiani G, Bésuelle P (eds). Advances in $X$-ray tomography for geomaterials. ISTE Ltd, London, UK: 341-348

Komine H. and Ogata N. (1999) Experimental study on swelling characteristics of sandbentonite mixture for nuclear waste disposal. Soils and Foundations 39 (2): 83-97. 
Kozaki T., Suzuki S., Kozai N., Sato S. and Ohashi H. (2001). Observation of microstructures of compacted bentonite by microfocus X-ray computerized tomography (Micro-CT). Journal of Nuclear Science Technology 38 (8), pp. 697-699

Li Z.M. (1995). Compressibility and collapsibility of compacted unsaturated loessial soils. Proceedingsof the $1^{\text {st }}$ International Conference on Unsaturated Soils UNSAT' 95 1, 139-144, Paris, Balkema, Rotterdam.

Lloret A., Villar M.V., Sanchez M., Gens A., Pintado X. \& Alonso E.E. 2003. mechanical behaviour of heavily compacted bentonite under high suction changes. Géotechnique 53 (1), 27-40.

Madsen FT. (1998). Clay mineralogical investigations related to nuclear waste disposal. Clay Minerals, 33(1):109-129.

Montes-H G. (2002) Etude expérimentale de la sorption d'eau et du gonflement des argiles par microscopie électronique à balayage environnementale (ESEM) et analyse digitale d'images. PhD Thesis. Université Louis Pasteur, Strasbourg, France.

Mukunoki T., Otani J., Maekawa A., Camp S., Gourc J.P. (2006). Investigation of crack behaviour on cover soils at landfill using X-ray CT. In: Desrues J, Viggiani G, Bésuelle P(eds) Advances in X-ray tomography for geomaterials. ISTE Ltd, London, UK: 213-219.

Pusch, R. (1979). Highly compacted sodium bentonite for isolating rock-deposited radioactive waste products. Nucl. Technol, United States. 45(2):153-157.

Rasband W.S. (1997-2012). ImageJ, U. S. National Institutes of Health, Bethesda, Maryland, USA, http://imagej.nih.gov/ij/.

Razavi M.R., Muhunthan B. and Al Hattamleh O. (2007) Representative elementary volume analysis using X-ray computed tomography, Geotechnical Testing Journal 30 (3), 212-219.

Rolland S., Stemmelen D., Moyne C. and Masrouri F. (2003). Transfert hydrique dans un sol argileux gonflant non saturé: influence du confinement. Revue Française de Géotechnique 104, 21-35

Rolland S., Stemmelen D., Moyne C. and Masrouri F. (2005). Experimental hydraulic measurements in an unsaturated swelling soil using the dual-energy gamma-ray technique. Proceedings of International Symposium on Advanced Experimental Unsaturated Soil Mechanics, Trento, Italy. In: Tarantino A, Romero E, Cui YJ (eds) Advanced experimental unsaturated soil mechanics. Taylor, Francis Group, London, 305-310.

Romero E., Gens A., and Lloret A. (1999). Water permeability, water retention and microstructure of unsaturated compacted Boom clay. Engineering Geology, 54 (1-2): 117-127.

Tang A.M., Cui Y.J. and Le T.T. (2008). A study on the thermal conductivity of compacted bentonites. Applied Clay Science; 41 (3-4):181-189.

Tarantino A. and De Col E. (2008). Compaction behaviour of clay. Géotechnique 58 (3): 199-213.

Van Geet M., Volckaert G. and Roels S. (2005). The use of microfocus x-ray computed tomography in characterising the hydration of a clay pellet/powder mixture. Applied Clay Science, 29 (2):73-87, 2005. 
525 Villar M.V. and Lloret A. (2001). Variation in the intrinsic permeability of expansive 526 clays upon saturation. In: Adachi K., Fukue M. (eds) Clay Science for Engineering . 527 A.A. Balkema, Rotterdam, 259-266.

528 Yong R.N., Boonsinsuk P. and Wong G. (1986). Formulation of backfill material for a 529 nuclear fuel waste disposal vault. Canadian Geotechnical Journal, 23(2):216-228.

530

531 


\section{$532 \quad$ List of figures}

Figure 1. Grain size distribution curves.

Figure 2. (a) Pore size distribution curve and (b) Cumulative porosity curve.

Figure 3. The 3D reconstructed image of the sample with the position of the cross section considered.

Figure 4. A typical horizontal $\mu \mathrm{CT}$ cross section of the compacted bentonite/sand mixture sample (dry density: $1.8 \mathrm{Mg} / \mathrm{m}^{3}$, water content: $10 \%$. Disk diameter is $50 \mathrm{~mm}$ ) . Figure 5. Histogram of the image (linear and logarithmic scale) with the fitted Gaussians and the obtained threshold value.

Figure 6. Images at different stages before segmentation: a) non-treated, b) after applying 3D median filter, c) during threshold and d) final segmented image.

Figure 7. Calculated porosity from different volumes and at different locations in the sample.

Figure 8. Studied volumes at different locations in the sample.

Figure 9. Porosity changes with respect to the position of the studied volume in the sample ( $\mathrm{x}$ and $\mathrm{y}$ ).

Figure 10. Concentric rings studied.

Figure 11 Changes in macro porosity with respect to the radius of the ring selected. 


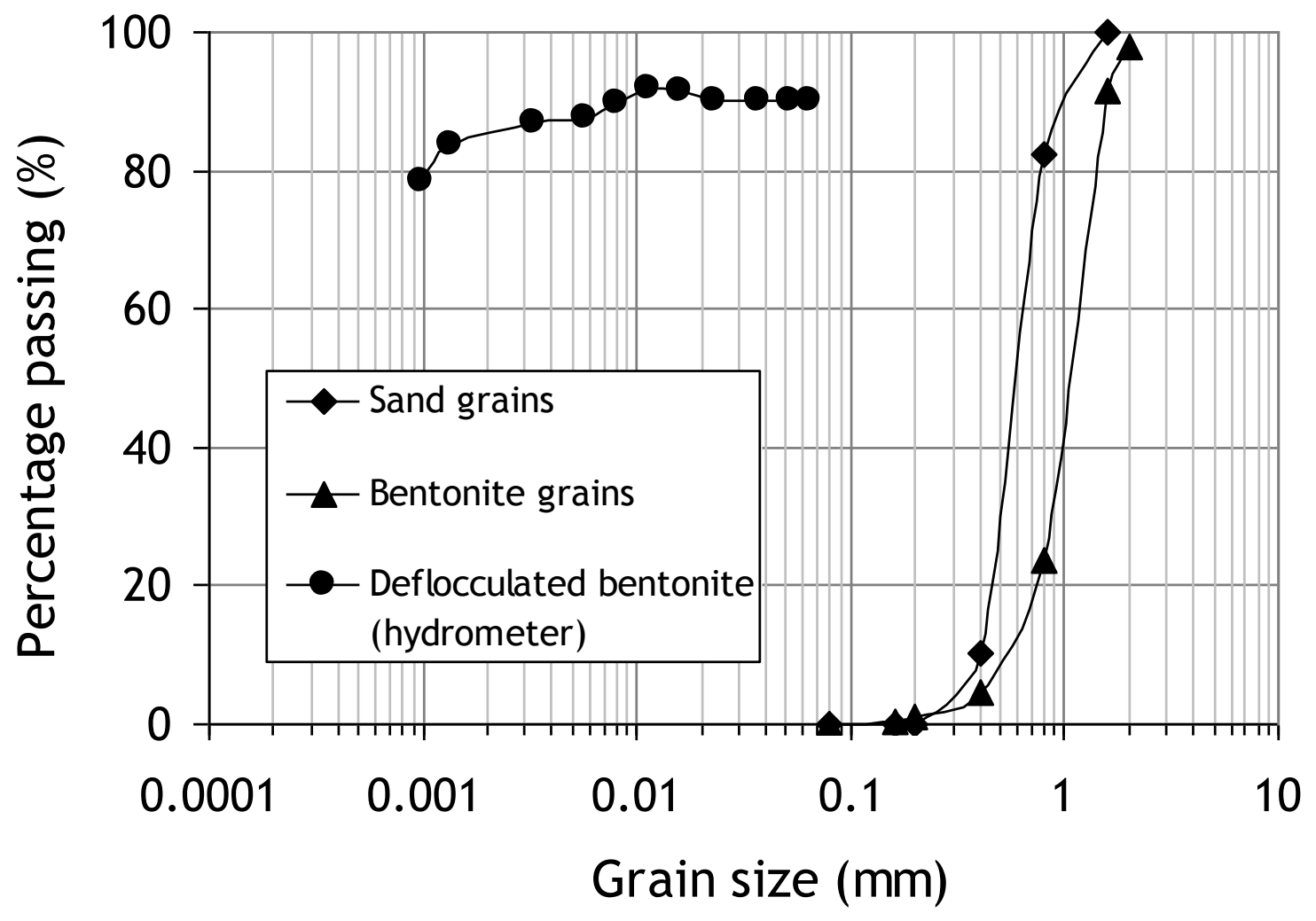

Figure 1. Grain size distribution curves. 


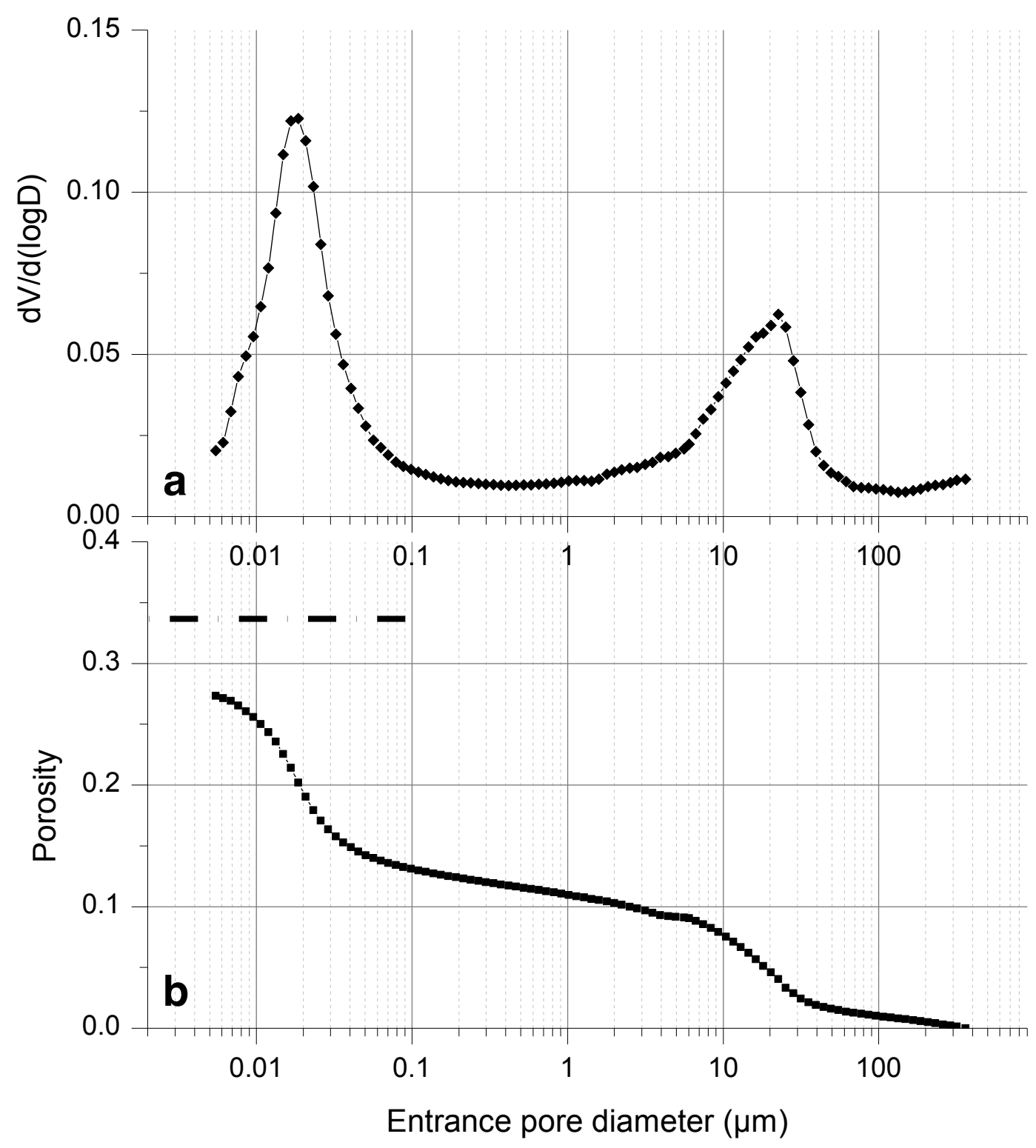

Figure 2. (a) Pore size distribution curve and (b) Cumulative porosity curve. 


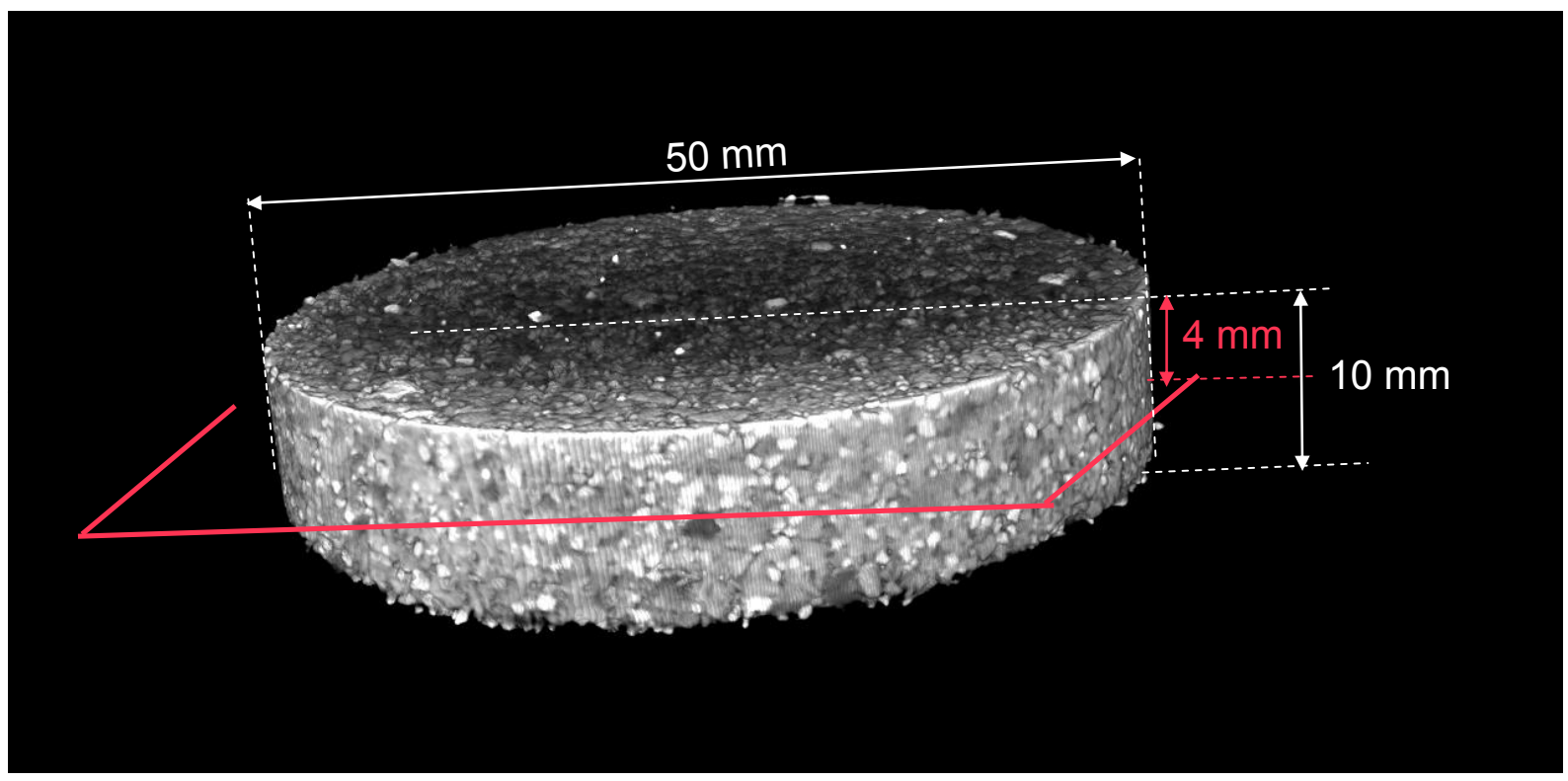

Figure 3. The 3D reconstructed image of the sample with the position of the cross section considered.

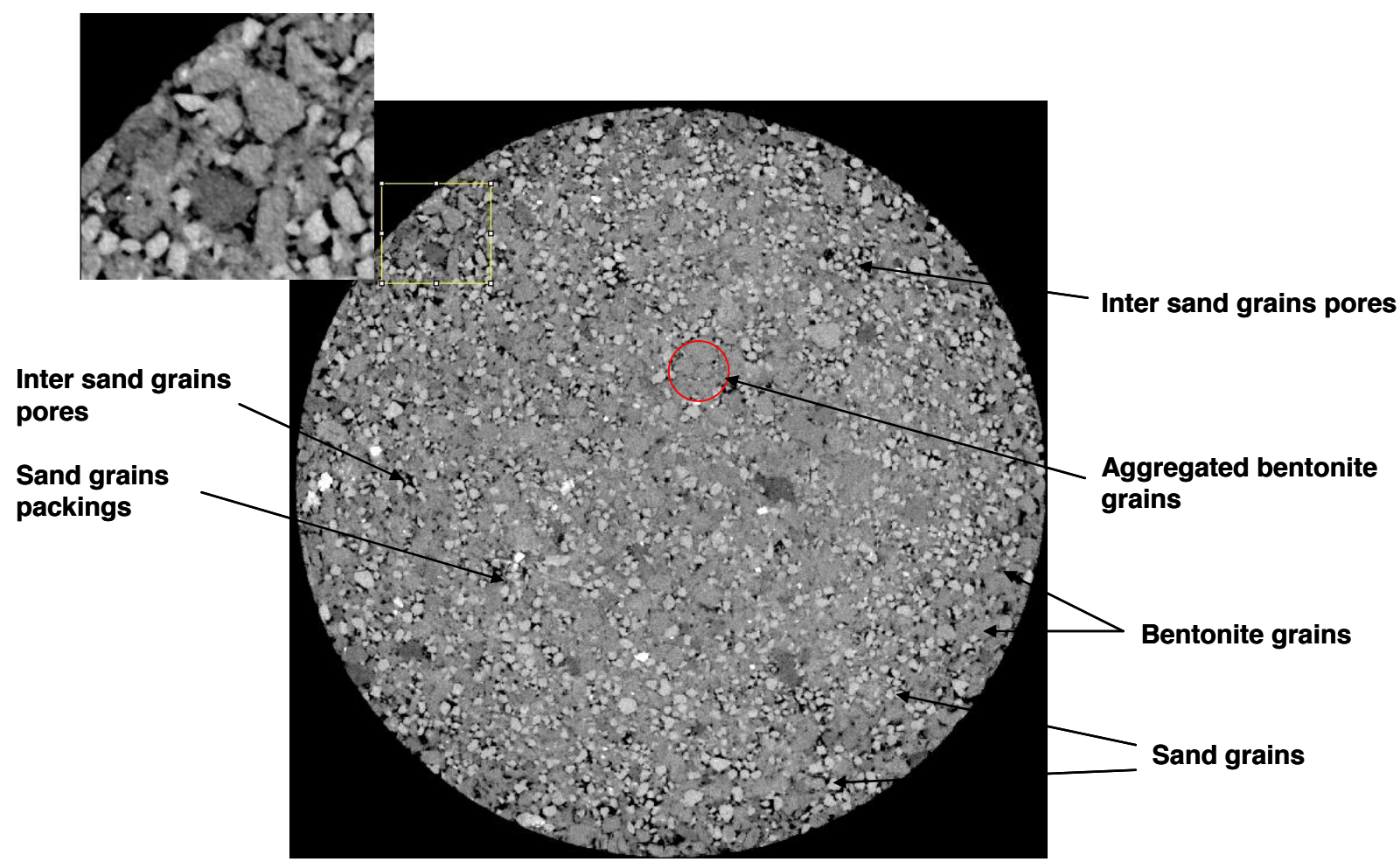

Figure 4. A typical horizontal $\mu \mathrm{CT}$ cross section of the compacted bentonite/sand mixture sample (dry density: $1.8 \mathrm{Mg} / \mathrm{m}^{3}$, water content: $10 \%$. disk diameter is $50 \mathrm{~mm}$ ). 


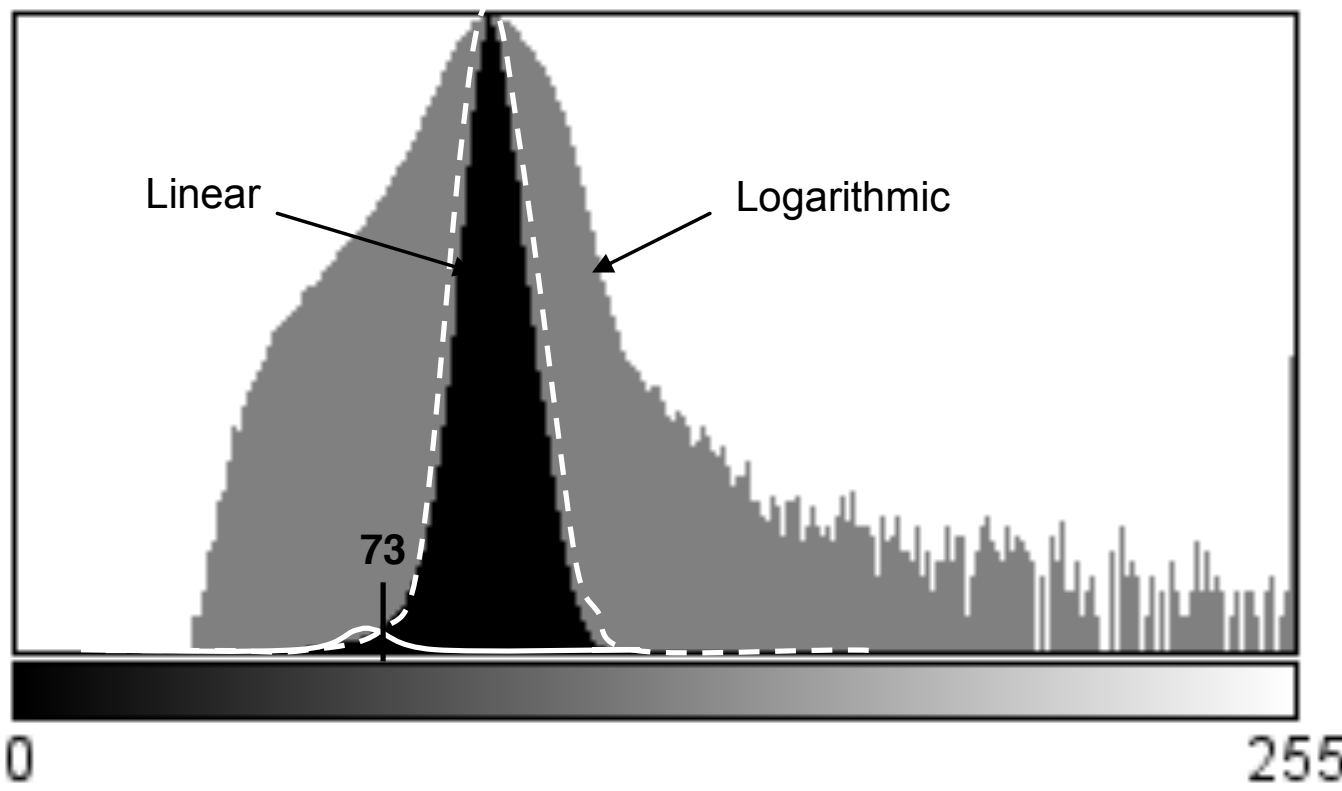

Figure 5. Histogram of the image (linear and logarithmic scale) with the fitted Gaussians and the obtained threshold value.

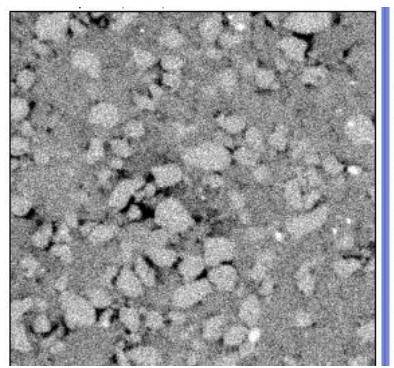

a)

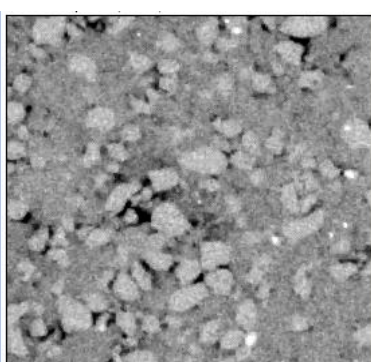

b)

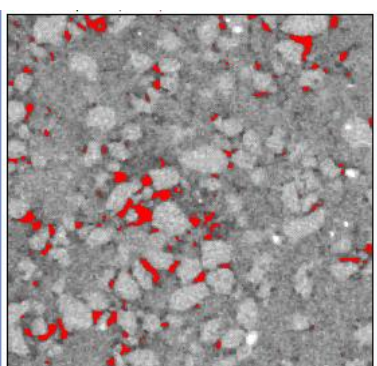

c)

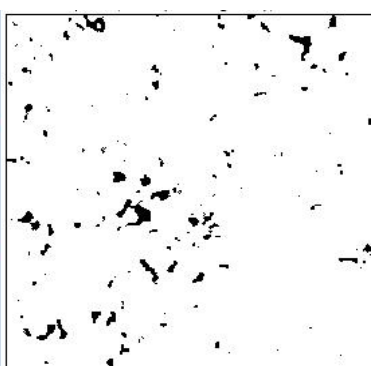

d)

Figure 6. Images at different stages before segmentation: a) non-treated, b) after applying 3D median filter, c) during threshold and d) final segmented image. 

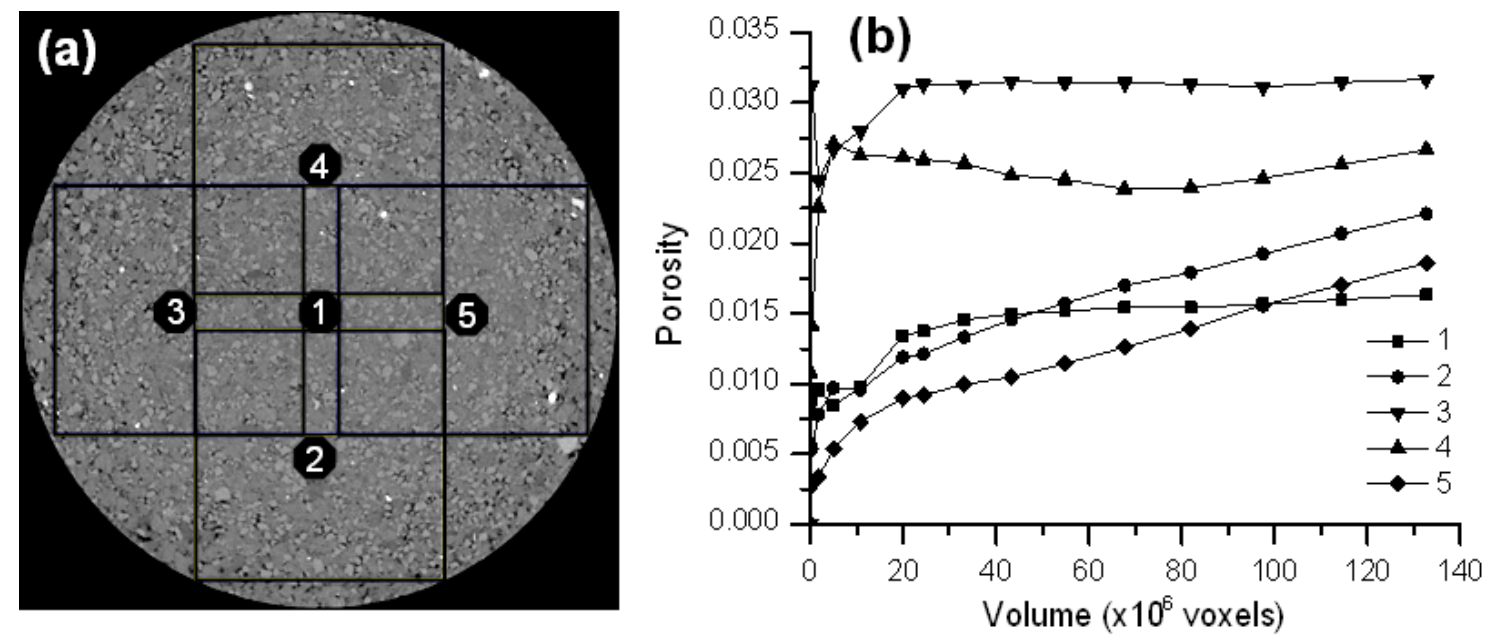

Figure 7. Calculated porosity for different volumes and at different locations in the sample.

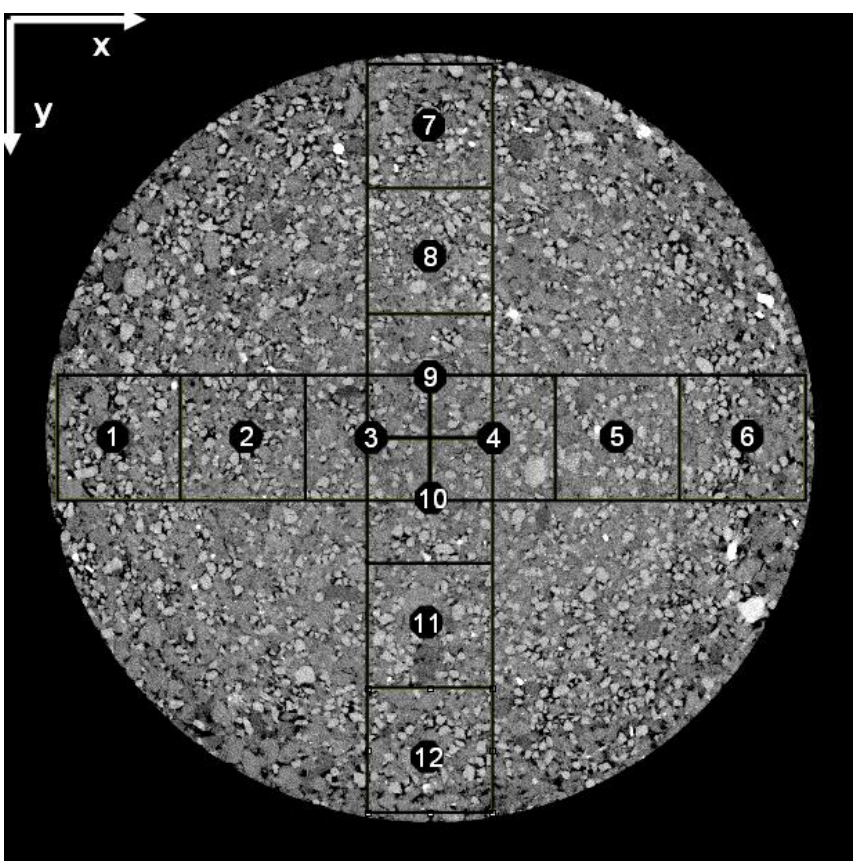

Figure 8. Sections of the volumes investigated in the sample (thickness 271 voxels). 


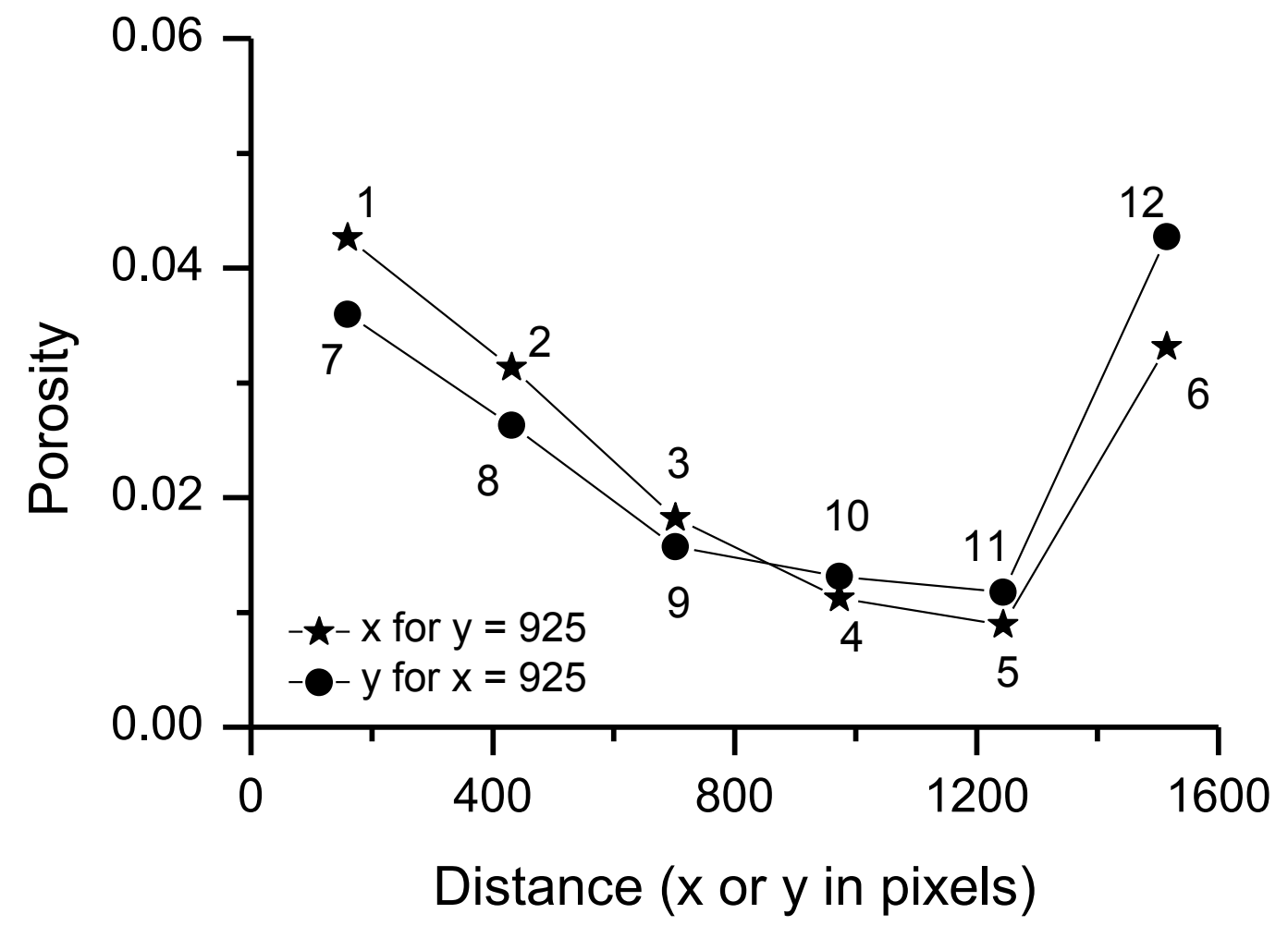

Figure 9. Porosity changes with respect to the position of the studied volume in the sample (x and y). 


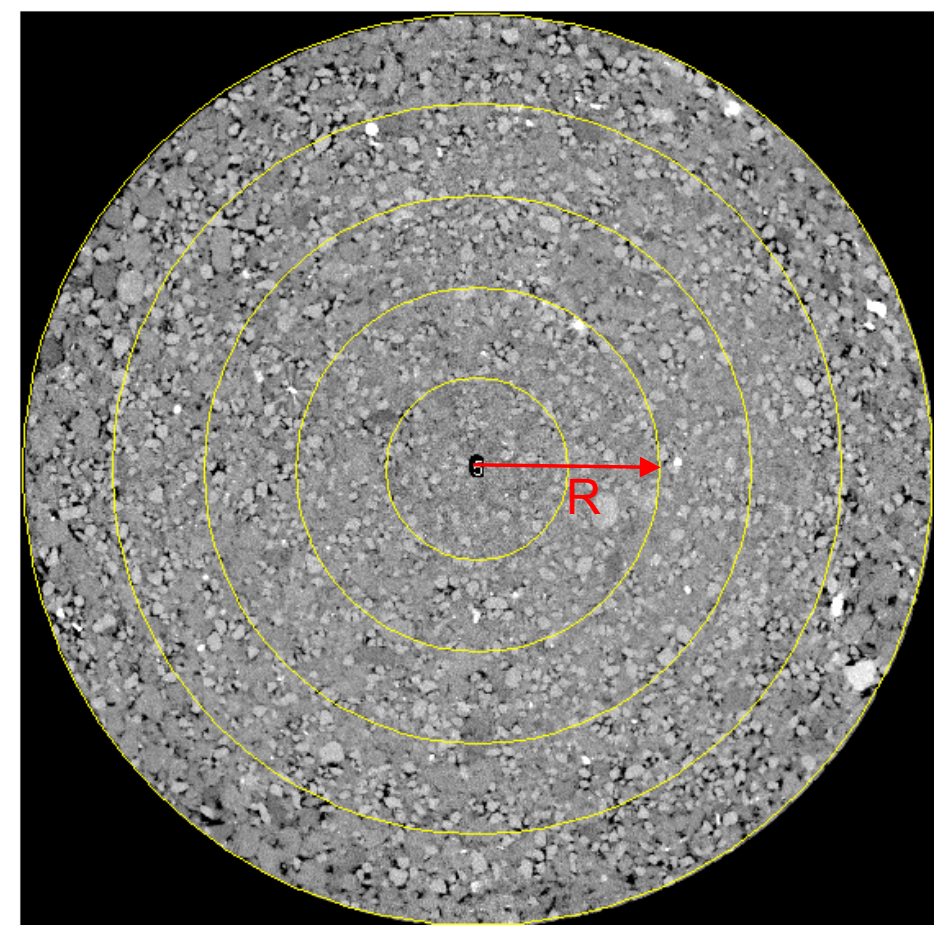

Figure 10. Concentric rings studied.

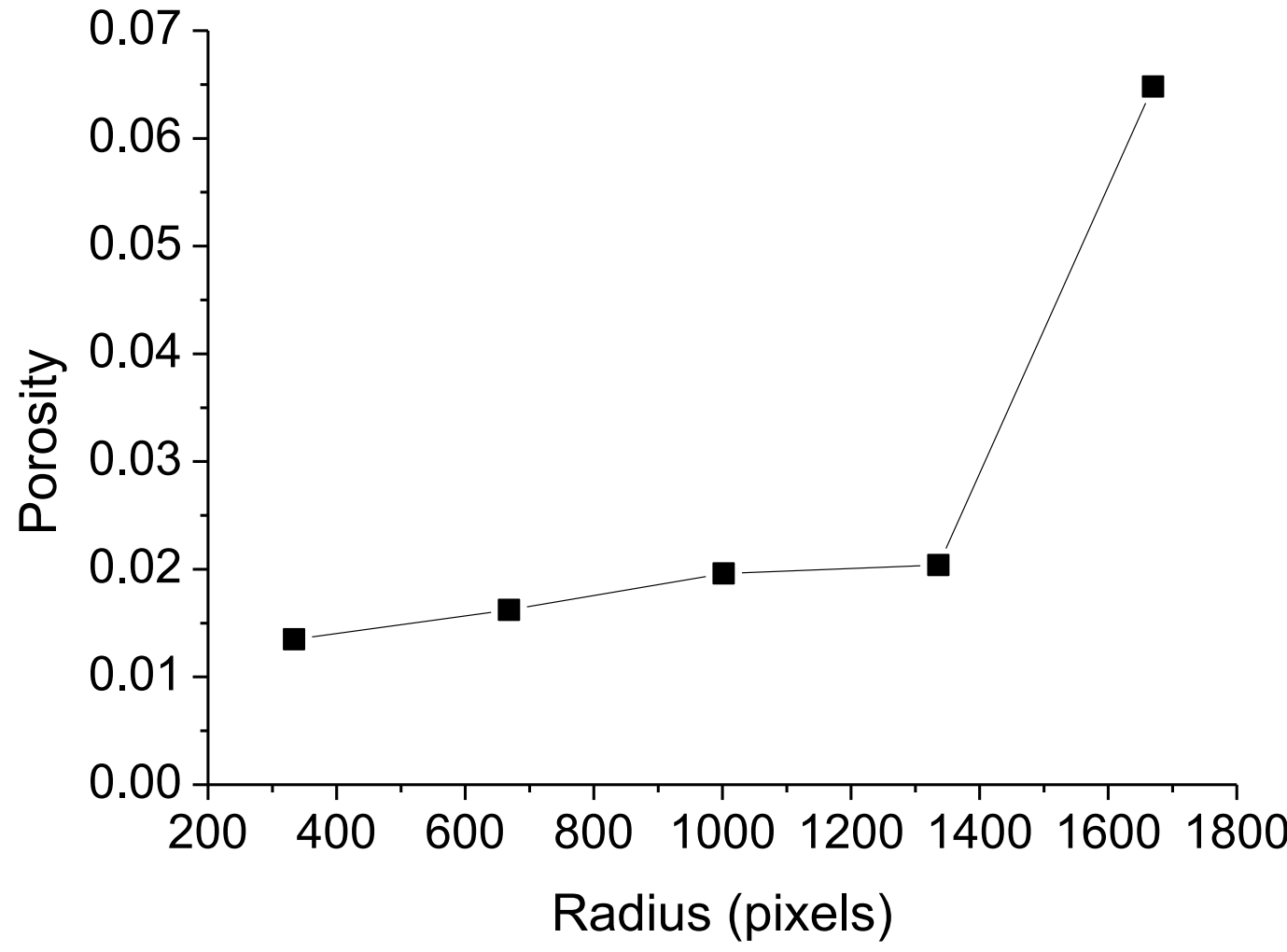

Figure 11. Changes in macro porosity with respect to the radius of the ring selected. 